Gut, 1987, 28, 40-46

\title{
Discriminant value of dyspeptic symptoms: a study of the clinical presentation of 221 patients with dyspepsia of unknown cause, peptic ulceration, and cholelithiasis
}

\author{
N J TALLEY, D McNEIL, AND D W PIPER \\ From the Department of Medicive, University of Sydney at Royal North Shore Hospital, St Leonard's, and \\ School of Economic and Financial Studies, Macquarie University, Sydney, Australia
}

SUMmARY This study aims to determine whether the features of dyspepsia can discriminate a subgroup of patients who present with non-ulcer dyspepsia from other diagnostic categories. The following groups were studied (1) One hundred and thirteen patients with endoscopically confirmed non-ulcer dyspepsia in the absence of clinical, biochemical or radiological evidence of other gastrointestinal diseases or disorders, termed essential dyspepsia; (2) Fifty five patients with symptomatic and endoscopically proven peptic ulceration (32 duodenal ulcers, 23 gastric ulcers); (3) Fifty three patients admitted to hospital with biliary pain and cholelithiasis without other lesion at laparotomy. All patients completed a structured history questionnaire at personal interview. Stepwise logistic regression analysis was done on 19 predefined variables to determine if one or more of these could discriminate between the diagnostic categories. The results suggest that certain groups of symptoms may be of diagnostic value, but many are not. Upper abdominal pain aggravated by food or milk, pain severity, night pain, vomiting, weight loss, and age significantly discriminated essential dyspepsia from the other diagnostic categories. A scoring system was established based on these discriminating symptoms. Using the weighted score, at a sensitivity of $57 \%$, the specificity for a diagnosis of essential dyspepsia was $94 \%$, but only prospective studies will determine if this scoring system is of actual clinical value.

Dyspepsia is an extremely common symptom with a prevalence in the community of approximately $30 \% .^{1}$ In 1905 Lord Moynihan declared that most cases of dyspepsia could be diagnosed by the symptoms alone. ${ }^{2}$ Recent studies have suggested, however, that patients who present with dyspepsia are often misdiagnosed. ${ }^{3}$ This may be because of the failure of doctors to elicit and analyse symptoms accurately, perhaps because of a faulty mental 'database' regarding the diagnostic value of dyspeptic symptoms. ${ }^{3-5}$ Horrocks and de Dombal in a computer-aided study found that the manifestations of disease in patients with peptic ulceration and functional dyspepsia differed in several respects from the typical picture described in textbooks 5

Address for correspondence: Professor D. W. Piper. Department of Medicine Royal North Shore Hospital, St Leonard's, 2065. New South Wales. Australia.

Received for publication 2 May 1986 although other authors continue to use arbitrarily defined 'classical ulcer symptoms' in their studies. ${ }^{67}$

Non-ulcer dyspepsia, also termed radiograph negative or functional dyspepsia, is a common but heterogeneous syndrome; the irritable bowel syndrome, gastro-oesophageal reflux, gall stones and other diseases may cause ulcer like symptoms. ${ }^{189}$ There is a sub-group of non-ulcer dyspepsia sufferers, however, comprising approximately one quarter of the patients with chronic dyspepsia, where the cause of the dyspepsia remains unexplained in terms of conventional knowledge; provisionally we have described these patients as suffering from "essential dyspepsia'. ${ }^{9}$ All previous studies ${ }^{5-7} 1(1-13$ have grouped together patients with these varying diseases and disorders under the heading non-ulcer dyspepsia or functional disease, and have not assessed the symptomatology of the various subgroups separately. 
The aim of the present study was, therefore, to determine whether specific symptoms or groups of symptoms could positively discriminate patients with essential dyspepsia from patients with peptic ulcer and cholelithiasis.

\section{Methods}

\section{DEFINITION OF TERMS}

Dyspepsia is defined as any pain, discomfort, or nausea referable to the upper alimentary tract which may be intermittent or continuous, has been present for one month or more, and is not precipitated by exertion and not relieved within five minutes by rest. ${ }^{18913}$ Patients with associated jaundice, dysphagia, or bleeding were excluded.

Non-ulcer dyspepsia is defined as dyspepsia where clinical evaluation reveals no evidence of organic disease that could be responsible for the dyspepsia, and endoscopy shows no evidence of acute or chronic peptic ulceration, oesophagitis or malignancy. ${ }^{5-13}$ The presence of chronic non-erosive gastroduodenitis is not an exclusion clause for this definition, as it remains uncertain whether such mucosal lesions are a cause of dyspepsia. ${ }^{6-8}+1+15$

Essential dyspepsia is defined as non-ulcer dyspepsia where biliary tract disease has been excluded radiologically, the irritable bowel syndrome and gastro-oesophageal reflux have been excluded by objective clinical criteria described elsewhere " and there is no evidence of other diseases which could explain the dyspepsia." "

\section{PATIENT SEIECTION}

\section{Essential dyspepsia patients}

The study group was chosen from 544 consecutive patients with endoscopically diagnosed non-ulcer dyspepsia. These patients were contacted first by letter and then by telephone, a well validated method of data collection. ${ }^{16} 17$ Data on organic disease was also collected from the patients local doctor, the medical records and the endoscopist.

Exclusion criteria were patients with other gastrointestinal disorders (the irritable bowel syndrome, gastro-oesophageal reflux, gall stones and pancreatitis (263 patients), ${ }^{8} 9$ a past history of gastric surgery (seven patients), inability to speak English (41 patients), overwhelming other mental or physical disease (such as disseminated carcinoma, liver disease, renal failure, bowel obstruction or major psychoses) (67 patients), residence outside the Sydney metropolitan region (eight patients), lack of a telephone (17 patients), endoscopic or radiological proof of peptic ulceration in the preceding six months (15 patients), and aged more than 85 years or less than 16 years (13 patients).
The remaining 113 patients had no known disorders associated with, and no detected cause for their dyspepsia, which we have termed essential dyspepsia. ${ }^{8}$ Included amongst these were 22 patients $(19 \%)$ with chronic gastritis or duodenitis macroscopically (patients with erosions at endoscopy were excluded). Twenty six patients $(23 \%)$ who complained of dyspepsia associated with abdominal distension and belching in the absence of other disorders we defined as having aerophagy: ${ }^{*}$ is as this disorder overlaps with essential dyspepsia, and as it has been shown to be unrelated to excessive intestinal gas, ${ }^{18}$ we included these patients in our essential dyspepsia group.

\section{Peptic ulcer patients}

Patients who had a history of dyspepsia with or without other symptoms, such as bleeding, and who were found at endoscopy to have either duodenal ulceration or gastric ulceration, were studied consecutively. Excluded were 10 patients with oesophagitis macroscopically, two with pyloric canal ulcers or combined lesions (duodenal ulcer plus gastric ulcer), two with a history of gastric surgery and 10 patients who, before endoscopy, had been on long term maintenance cimetidine therapy which may have altered the natural history of the presenting symptoms. Also excluded were five patients with overwhelming other mental or physical diseases and six patients who were non-English speaking.

The final sample of 32 patients with duodenal ulceration and 23 patients with gastric ulceration were otherwise unselected.

\section{Cholelithiasis patients}

Fifty three consecutive patients admitted for biliary pain caused by gall stones (confirmed radiologically) were studied. Entry criteria for the study were abdominal pain in the six months before admission, absence of a peptic ulcer history, and the absence at laparotomy of any other lesion except gall stones. Two patients with other overwhelming diseases were excluded. Patients were otherwise unselected. Seven patients with biliary pain $(13 \%)$ were endoscoped at the discretion of the attending surgeon; only one had chronic gastroduodenitis and none had peptic ulceration.

\section{DATA COLLECTION}

All patients in the three diagnostic groups were interviewed personally by the one investigator (NJT) and a predefined, detailed, structured history questionnaire, which enquired about symptoms in a standard fashion, was completed (Table 1). The possibility of bias is acknowledged. This was further minimised by the patients being unaware of the 
Table 1 Predefined variables assessed for predictive value in each diagnostic category (essential dyspepsia, peptic ulcer and cholelithiasis)

A SYMPTOMS

1 'Classical ulcer symptoms (Greenlaw et al 1980) (1) or 1) Criteria: 2 or more of the following:

(i) Epigastric pain relieved by food, milk or antacids

(ii) Periodicity of epigastric pain

(iii) Post prandial epigastric pain

(iv) Nocturnal epigastric pain (- that is, woken from sleep)

2 Pain localised to the epigastrium only ( $(1)$ or 1 )

3 Pain severity (()-4)

() Nil

1 Mild: can be ignored if the patient does not think about it

2 Moderate: cannot be ignored but does not influence daily activitics

3 Severe: influences concentration on daily activities

4 Very severe: markedly influences daily activities and/or requires rest

4 Intermittent vs continuous pain (any site) (0 or 1 )

5 Length of attack of pain $((1-3)$

() Nil

$1<1 / 2$ hour

$2 \geq 1 / 2$ hour to $<6$ hours

$3>6$ hours

6 Pain radiating to the back (0) or 1 )

7 Night pain - that is, pain at any site which wakes the patient from sleep ( $(0$ or 1$)$

8 Pain occurring before meals or when hungry (at any site) (1) or 1)

9 Pain half to three hours after meals (any site) (0 or 1)

10) Pain aggravated by food or milk (0) or 1$)$

11 Pain aggravated by alcohol ( $(0$ or 1$)$

12 Pain relieved by food. milk or antacids (any site) (() or 1)

13 Pain relieved by vomiting (1) or 1$)$

14 Nausea (0) or 1$)$

15 Vomiting $(0$ or 1$)$

16 Anorexia (0) or 1)

17 Weight loss $(\geq 3 \mathrm{~kg})(0$ or 1$)$

B COVARIABLES

1 Age (continuous variable in years)

2 Sex

object of the questionnaire and by the variety and number of the questions; answers were not prompted by the interviewer. Of those eligible, $95 \%$ agreed to participate.

Previous studies had suggested that certain features of abdominal pain and other symptoms, such as vomiting and weight loss, may be of some value as discriminators in dyspepsia, although characteristic differences were often not definable. ${ }^{510-13}$ Arbitrarily, 17 symptoms considered likely to be of most value, based on these studies, were selected for this investigation.

The ethical aspects of the study were approved by the Medical Ethics Review Committee of the Royal North Shore Hospital, Sydney.

STATISTICAL ANALYSIS

From each patient data on age, sex and the 17 predefined symptom variables were analysed using the Macquarie University VAX Computer (Table 1). For each of the diagnostic categories (essential dyspepsia, peptic ulceration, cholelithiasis) in turn a discriminant function based on logistic regression ${ }^{19} 20$ was used for the allocation of patients to that category, where the patients in the other two categories constituted the control group. Thus each patient had a different probability of belonging to the category in question. Any variables that were not significant at the 0.05 level were excluded, and the analysis was repeated until a final model was established for each diagnostic category (Table 2). The alpha level of $0 \cdot 05$ was taken so as not to exclude important discriminating symptoms.

The probability that a particular patient (i) was a case in a specified diagnostic category was calculated from:

$$
\text { Probability }=\frac{1}{1+e^{-[\text {constant }+\Sigma B j \text { Xij }]}}
$$

where $B_{j}$ is the value of the coefficient for symptom $\mathrm{j}$ and $\mathrm{X}_{\mathrm{ij}}$ is the response of patient $\mathrm{i}$ to symptom $\mathrm{j}$. It should be noted that whilst the coefficients in this formula are estimated using knowledge of which

Table 2 Stepwise logistic regression of symptoms, age and sex by diagnostic category: significant variables

\begin{tabular}{|c|c|c|}
\hline Variables & $\begin{array}{l}\text { Regression } \\
\text { coefficient }\end{array}$ & $p$-value \\
\hline \multicolumn{3}{|l|}{$\begin{array}{l}1 \text { Essential dyspepsia vs peptic ulcer } \\
\text { +cholelithiasis }\end{array}$} \\
\hline Constant & $5 \cdot 29$ & $<0.001$ \\
\hline A Food or milk aggravates pain & $0 \cdot 88$ & 0.017 \\
\hline B Pain severity & $-0 \cdot 84$ & $<0.001$ \\
\hline C Night pain & -0.99 & $0 \cdot 004$ \\
\hline D Vomiting & $-1 \cdot 38$ & $0 \cdot 001$ \\
\hline E Weight loss & $-0 \cdot 82$ & $0 \cdot 046$ \\
\hline F Age & $-0 \cdot 04$ & $<0 \cdot 001$ \\
\hline \multicolumn{3}{|l|}{$\begin{array}{l}2 \text { Peptic ulceration } v s \text { essential dyspepsia } \\
\text { +cholelithiasis }\end{array}$} \\
\hline Constant & $-3 \cdot 37$ & 0.001 \\
\hline C Night pain & $1 \cdot 40$ & $<0.001$ \\
\hline G Food, milk, antacids relieve pain & $1 \cdot 74$ & $<0 \cdot 001$ \\
\hline H Length of pain episodes & $-0 \cdot 59$ & $0 \cdot 018$ \\
\hline F Age & $0 \cdot 03$ & 0.025 \\
\hline \multicolumn{3}{|l|}{$\begin{array}{l}3 \text { Cholelithiasis vs essential dyspepsia } \\
\text { +peptic ulcer }\end{array}$} \\
\hline Constant & $-6 \cdot 62$ & $<0.001$ \\
\hline B Pain severity & 1.77 & $<0.001$ \\
\hline I Localised to epigastrium & $-2 \cdot 65$ & $<0 \cdot 001$ \\
\hline G Food, milk, antacids relieve pain & $-2 \cdot 15$ & $<0.001$ \\
\hline J Pain before meals & $-2 \cdot 05$ & $0 \cdot 005$ \\
\hline F Age & $0 \cdot 04$ & $0 \cdot 010$ \\
\hline
\end{tabular}


patients belong to the various categories, the formula is meant to be applied to patients whose diagnosis is unknown. Also the formula applies only to prediction of each diagnostic category separately. To predict multiple diagnoses a different approach would be needed; besides being statistically complicated, this was not considered appropriate to fulfil the aims of this study.

The significant coefficients obtained from the logistic regression analysis may be regarded as contributing to an integer score, obtained simply by multiplying the coefficient by 10 and rounding. This score reflects the probability of correctly diagnosing the case.

The sensitivity of a test is defined as the proportion of subjects with a disorder who have a positive or abnormal test for the disorder, whilst the specificity is the proportion of subjects without the disorder who have a negative or normal test. Given the results of a test, the probability of the disorder is called the predictive value of the test. Positive predictive value is the probability of a disorder in a patient with a positive test result, whilst negative predictive value is the probability of not having the disorder with a negative test result. The more sensitive a test is, the better the negative predictive value; alternatively, the more specific a test is, the better is the positive predictive value.

The sensitivity, specificity, and predictive values were calculated for the diagnostic symptom scores based on the results of the logistic regression analysis. Critical score values for the symptoms were then constructed based on their sensitivity and specificity to determine the most useful criteria for diagnosis.

\section{Results}

The median age for patients with essential dyspepsia was 48 years, duodenal ulcer 53 years, gastric ulcer 59 years and cholelithiasis 53 years. Women outnumbered men in patients with essential dyspepsia (1.5:1), gastric ulcer (1.9:1) and cholelithiasis $(2 \cdot 8: 1)$. In duodenal ulcer men predominated $(1 \cdot 5: 1)$.

The mean values and ranges for symptoms in each diagnostic category are given in Table 3 . The results of the stepwise logistic regression are presented in Table 2. Analysis of the 17 symptom variables assessed, showed: (1) A diagnosis of essential dyspepsia was more likely if: food or milk aggravated the patient's upper abdominal pain $(p=0.017)$, the pain was less severe $(p<0.001)$, there was no history of night pain waking the patient from sleep $(p=0 \cdot 004)$, there was no vomiting $(p=0.001)$ and there was no history of weight loss of three or more kilograms $(p=0 \cdot 046)$. (2) A diagnosis of peptic ulceration was more likely if: there was night pain $(p<0 \cdot 001)$, food, milk or antacids relieved the pain $(p<0.001)$, and pain episodes were of shorter duration $(p=0 \cdot 018)$. (3) A diagnosis of cholelithiasis was more likely if: pain was more severe $(p<0.001)$, pain was not localised to only the epigastrium $(p<0.001)$, food, milk or antacids did not relieve the pain $(p<0.001)$ and pain was not present before meals $(p=0 \cdot 005)$.

Table 3 Mean values for symptoms (as defined in Table I) in each diagnostic category

\begin{tabular}{|c|c|c|c|c|c|c|}
\hline & $\begin{array}{l}\text { Essential } \\
\text { dyspepsia } \\
(n=113)\end{array}$ & $\begin{array}{l}\text { Peptic } \\
\text { ulcer } \\
(n=55)\end{array}$ & $\begin{array}{l}\text { Cholelithiasis } \\
\text { patients } \\
(n=5.3)\end{array}$ & $\begin{array}{l}\text { All } \\
\text { patients } \\
(n=221)\end{array}$ & $\begin{array}{l}\text { Min } \\
\text { value }\end{array}$ & $\begin{array}{l}\text { Max } \\
\text { value }\end{array}$ \\
\hline ‘Classical ulcer symptoms’ & 0.47 & 0.64 & $0 \cdot 23$ & 0.45 & 0 & 1 \\
\hline Pain localised to epigastrium & 0.53 & 0.62 & 0.17 & $(0.47$ & () & 1 \\
\hline Pain severity & $2 \cdot 24$ & $2 \cdot 53$ & $3 \cdot 60$ & $2 \cdot 64$ & () & 4 \\
\hline Intermittent $v s$ continuous & 0.55 & 0.58 & 0.87 & 0.63 & () & 1 \\
\hline Length of pain & $2 \cdot 26$ & $2 \cdot() 4$ & $2 \cdot 28$ & $2 \cdot 21$ & () & 3 \\
\hline Radiation to back & $0 \cdot 27$ & 0.35 & 0.55 & $0 \cdot 36$ & () & 1 \\
\hline Night pain & 0.42 & 0.75 & $(0 \cdot 60$ & 0.54 & () & 1 \\
\hline Pain before meals & 0.42 & 0.42 & $0 \cdot 06$ & 0.33 & 0 & 1 \\
\hline Post prandial pain & $0 \cdot 50$ & 0.55 & 0.43 & $(0.50$ & () & 1 \\
\hline Pain aggravated by food or milk & 0.41 & 0.29 & 0.11 & $(0 \cdot 31$ & () & 1 \\
\hline Pain aggravated by alcohol & $0 \cdot 28$ & $0 \cdot 36$ & $0 \cdot(14$ & $0 \cdot 24$ & () & 1 \\
\hline Pain relieved by food, milk, antacids & 0.73 & 0.89 & $(1) .32$ & $(0.67$ & () & 1 \\
\hline Nausea & 0.49 & 0.58 & 0.64 & 0.55 & () & 1 \\
\hline Vomiting & $0 \cdot 14$ & $0 \cdot 38$ & 0.49 & $0 \cdot 29$ & () & 1 \\
\hline Anorexia & $0 \cdot 30$ & 0.40 & 0.23 & 0.31 & () & 1 \\
\hline Weight loss & 0.18 & $0 \cdot 31$ & $0 \cdot 30$ & $0 \cdot 24$ & 0 & 1 \\
\hline
\end{tabular}


The probability of a patient of certain age and with certain symptoms being a case in one of the diagnostic categories can be calculated from Tables 1 and 2 using the formula given in the Statistical Analysis section. For example, the probability of essential dyspepsia in a 53 year old patient who presented with mild pain aggravated by food, and who had no history of night pain, vomiting or weight loss, was $96 \%$. The probability of biliary pain was $69 \%$ if the patient was 53 years of age and presented with severe pain not localised to the epigastrium, which was unrelated to meals and not relieved by food, milk or antacids. Similarly, the probability of peptic ulceration in a 53 year old patient who presented with pain episodes lasting from 30 minutes to less than six hours, night pain, and pain relieved by food, was $54 \%$.

A more practical approach to patient diagnosis involves calculating a score by taking a weighted combination of relevant symptoms. For the diagnosis of essential dyspepsia, the weights may be computed by multiplying the coefficients obtained from the logistic regression model by 10 and rounding them to integers (or $0 \cdot 1$ in the case of age). The score for a particular patient is then obtained by multiplying these weights by the patient's responses to the corresponding symptoms, summing these components, and adding 100. (Adding 100 gives scores greater than zero).

Using the data in Table 2, the score function for diagnosing essential dyspepsia is thus

$$
100+9(\mathrm{~A})-8(\mathrm{~B})-10(\mathrm{C})-14(\mathrm{D})-8(\mathrm{E})-0 \cdot 4(\mathrm{~F})
$$

The specificity and sensitivity of symptoms based on this score are given in Table 4. A score of 60 points or more would give a diagnosis of essential dyspepsia with a specificity of $94 \%$ and a sensitivity of $57 \%$. A score of less than 40 points would give a diagnosis of organic disease (peptic ulcer or cholelithiasis) with a specificity of $92 \%$ and a sensitivity of $48 \%$. A score between 40 and 60 was of minimal value.

The predictive value of a test is determined
Table 5 The relation between the prevalence of essential dyspepsia and the predictive accuracy of a scoring system for its diagnosis

\begin{tabular}{lll}
\hline & $\begin{array}{l}\text { Positive predictive } \\
\text { value of essential } \\
\text { dyspepsia given }\end{array}$ & $\begin{array}{l}\text { Negative predictive } \\
\text { value of essential } \\
\text { dyspepsia given } \\
\text { score } \geq 60 \text { points (\%) }\end{array}$ \\
$\begin{array}{l}\text { Prevere }<40 \text { points (\%) } \\
(\%)\end{array}$ & \\
& & 91 \\
20 & 70 & 80 \\
40 & 86 & 63 \\
60 & 93 & 39 \\
80 & 97 & \\
\hline
\end{tabular}

according to Bayes theorem by the sensitivity and specificity of the test and by the prevalence of the disorder in the population being tested. In Table 5 the positive and negative predictive values for the diagnosis of essential dyspepsia in relation to different prevalences are listed.

\section{Discussion}

The diagnosis of dyspepsia is still considered to depend on a detailed history, despite the sophistication of available investigations. ${ }^{3}$ Although dyspepsia is extremely common, ${ }^{\prime}$ only approximately $45-50 \%$ of adults are correctly diagnosed when first seen in hospital. 22122 Diagnostic accuracy has been shown to be increased by $20-30 \%$ with the use of a predefined structured history questionnaire. ${ }^{2.3}$ Despite this approach, there remain difficulties with the diagnosis of the cause of dyspepsia for several reasons. Firstly, there are no universally accepted definitions of foregut symptoms, and even the term 'dyspepsia' itself has over 20 different definitions. ${ }^{3}$ Secondly, there are many causes for dyspepsia, yet there are relatively few symptoms by which the cause manifests itself, and no reliable physical signs in most instances. ${ }^{13}$ Finally, the discriminatory value of foregut symptoms in distinguishing the common causes of dyspepsia has been little studied until recently. ${ }^{3}$

Of the few outstanding studies that have com-

Table 4 Diagnostic scores for essential dyspepsia: sensitivity and specificity

\begin{tabular}{lllll}
\hline & $\begin{array}{l}\text { Patients with } \\
\text { essential dyspepsia } \\
(n=11.3)\end{array}$ & $\begin{array}{l}\text { Patients with organic } \\
\text { disease (peptic ulcer and } \\
\text { cholelithiasis) }(n=108)\end{array}$ & Sensitivity & Specificity \\
Diagnostic score & 9 & 52 & $8 \%$ & $52 \%$ \\
$0-39$ & 40 & 49 & $35 \%$ & $55 \%$ \\
$40-59$ & 64 & 7 & $57 \%$ & $94 \%$ \\
$60+$ & & & $5 \%$ & \\
\hline
\end{tabular}


pared the symptomatology of non-ulcer dyspepsia with other causes of dyspepsia, most have concluded that there was such an overlap between the symptoms of all the groups that characteristic differences were not definable. ${ }^{51(1-1,3}$ Although not all studies have agreed, certain features have been found to be more suggestive of a diagnosis of non-ulcer dyspepsia, such as the absence of night pain, pain made worse by eating, pain within one hour of a meal, the absence of vomiting and the absence of weight loss, but their importance has not usually been quantified. 5112

Most of these studies have suffered from some definite methodological problems. Firstly, methods of gathering clinical data have varied and diagnosis has mostly been based on barium meal, which has been suggested to miss $10-20 \%$ of ulcers and poorly diagnoses oesophagitis. ${ }^{12}{ }^{24}$ Secondly, previous studies have tended to group all non-organic disease patients in the functional disease category, so that patients with the irritable bowel syndrome, gastrooesophageal reflux without oesophagitis and other syndromes have been studied collectively, as if they suffer from one disorder, which may partly explain the inability of some investigations to discriminate by symptoms between the diagnostic categories. Finally, there has been a tendency to analyse subgroups in some of these studies rather than analysing all of the data collectively and adjusting for covariables; the former methodology increases the chances of finding a clinically unimportant significant result. ${ }^{25}$

In this study, all terms and syndromes were strictly defined prospectively, all patients with nonulcer dyspepsia and peptic ulcer were examined endoscopically, all interviews were carried out by one investigator using a structured history questionnaire to minimise observer variation, and stepwise logistic regression analysis was undertaken to estimate the probability that certain predefined variables distinguished each group from the others.

The limitations of this study must also be considered. Firstly, the results apply to a study population in which the three diagnostic categories are present; whether the results can be extrapolated to the situation when other organic diseases such as gastric cancer cause dyspepsia requires additional study. Secondly, although attempts were made to minimise bias, the investigation was not 'blinded', which may have resulted in unrecognised bias. The development of a scoring system also tends to be systematically biased towards optimism. ${ }^{26}$ To prove the findings have general validity the data need to be applied to an unselected and undiagnosed new set of patients prospectively in further studies.

The results do suggest that certain symptoms are of discriminatory value in dyspepsia, but many are not. For example, the present study found that the relationship between dyspepsia and the timing of meals was of minimal value in diagnosing peptic ulceration or excluding essential dyspepsia, and this is consistent with previous work. " $"$ It has been proposed that traditional textbook descriptions of peptic ulcer symptoms may be somewhat misleading: $:^{3}$ this and other studies ${ }^{5} 10-1.327$ appear to confirm this opinion. Greenlaw and coworkers have arbitrarily defined five symptoms (epigastric pain relieved by food or antacids, periodic epigastric pain, postprandial epigastric pain, nocturnal epigastric pain, and bleeding) and one sign (epigastric tenderness) as being classical ulcer features; they found two or more of these correlated with the presence of peptic ulceration and gastroduodenitis." 7 In this investigation, only the first four symptoms were studied; the presence of gastrointestinal bleeding was not included as there is no doubt that this is an indicator of the presence of a gastrointestinal lesion, and epigastric tenderness as a sign has been clearly shown to lack sensitivity and specificity. ${ }^{28}$ The present study found that the presence or absence of two or more of the remaining socalled classical ulcer symptoms were in fact, of no discriminating value in diagnosing dyspepsia.

The results thus suggest that patterns of symptoms can be helpful in indicating a diagnosis for the underlying cause of dyspepsia. It must be emphasised that discriminatory symptoms, which are therefore of diagnostic value, may not efficiently describe the disease; in addition, symptoms may provide a great deal of information by their absence. ${ }^{27}$ In this study, the diagnosis of essential dyspepsia was much more likely than peptic ulcer and cholelithiasis if a patient complained of upper abdominal pain which was not severe and was aggravated by food or milk, in the absence of a history of night pain, vomiting or weight loss. Using a weighted scoring system, at a sensitivity of $57 \%$, the specificity for diagnosis was $94 \%$ but only prospective studies will determine if this scoring system is of actual clinical value.

Although it has been stated that 'dyspepsia often defeats diagnosis, ${ }^{24}$ it is becoming clearer that careful history taking from dyspeptic patients with correct elicitation and analysis of symptoms may still be of major diagnostic value. ${ }^{3} 527$

This work was supported by the National Health and Medical Research Council. The help of Associate Professor Berry is gratefully acknowledged.

\section{References}

1 Krag E. Non-ulcer dyspepsia. Introduction: epidemi- 
ological data. Scand J Gastroenterol 1982; 17: Suppl 79: 6-8.

2 Moynihan BGA. On duodenal ulcer: with notes of 52 operations. Lancet 1905; 1: 340-6.

3 de Dombal FT. Analysis of foregut symptoms. In: Baron JH, Moody FG, eds. Butterworth's International Medical Review. Gastroenterology: I Foregut. London: Butterworths, 1981: 49-66.

4 Weed LL. Medical records, medical education and patient care. Cleveland, Ohio: Press of Case Western Reserve University, 1971.

5 Horrocks, JD, de Dombal FT. Clinical presentation of patients with 'dyspepsia': detailed symptomatic study of 360 patients. Gut 1978; 19: 19-26.

6 Greenlaw R, Sheahan DG, De Luca V, et al. Gastroduodenitis. A broader concept of peptic ulcer disease. Dig Dis Sci 1980; 25: 660-72.

7 De Luca VA, Winnan GG, Sheahan DG, et al. Is gastroduodentis part of the spectrum of peptic ulcer disease? J Clin Gastroenterol 1981; 3: suppl 2: 17-22.

8 Talley NJ, Piper DW. The association between nonulcer dyspepsia and other gastrointestinal disorders. Scand J Gastroenterol 1985; 20: 896-900.

9 Talley NJ, Fung LH, Gillian IJ, McNeil D, Piper DW. The association of anxiety, neuroticism and depression with dyspepsia of unknown cause: a case control study. Gastroenterology 1986; 90: 886-92.

10 Lawson MJ, Kerr Grant A, Paull A, Read TR. Significance of nocturnal abdominal pain: a prospective study. Bri Med J 1980; 2: 1302.

11 Edwards FC, Coghill NF. Clinical manifestations in patients with chronic atropic gastritis, gastric ulcer and duodenal ulcer. $Q J$ Med 1968; 37: 337-60.

12 Mollman KM, Bonnevie O, Gudman-Hoyer E, Wulff HR. Nosography of x-ray negative dyspepsia. Scand J Gastroenterol 1976; 11: 193-7.

13 Crean GP, Card WI, Beattie AD, et al. 'Ulcer-like dyspepsia'. Scand J Gastroenterol 1982; 17: Suppl 79: 9-15.

14 Cheli R. Symptoms in chronic non-specific duodenitis. Scand J Gastroenterol 1982; 17: Suppl 79: 84-6.

15 Kreuning J, Bossman FT, Kuiper G, Van Der Wal
AM, Lindeman J. Gastric and duodenal mucosa in 'healthy' individuals. J Clin Pathol 1978; 31: 69-77.

16 Hochstim JR. A critical comparison of three strategies of collecting data from households. J Amer Stat Assoc 1967; 62: 976-89.

17 Rogers TF. Interview by telephone and in person: quality of responses and field performance. Publ Opinion $Q$ 1976; 40: 51-65.

18 Levitt $\mathrm{MD}$, Bond $\mathrm{JH}$. The role of intestinal gas in functional abdominal pain. In: Chey WY, ed. Functional disorders of the digestive tract. New York: Raven Press, 1983: 245-9.

19 Dash Software Development Group. Division of biostatistics and epidemiology. Boston, Massachussetts, Dana-Farber Cancer Institute.

20 Breslow NE, Day NE. Statistical methods in cancer research. vol. 1. The analysis of case-control studies. Lyon: International Agency for research on Cancer, 1980.

21 Ross P, Dutton AM. Computer analysis of symptom complexes in patients having upper gastrointestinal examination. Am J Dig Dis 1977; 17: 248-54.

22 Horrocks JC, de Dombal FT. Computer aided diagnosis of dyspepsia. Am J Dig Dis 1975; 20: 397-406.

23 Horrocks JC, de Dombal FT. Diagnosis of dyspepsia using data collected by a 'physician assistant'. Br Med J 1975; 3: 421-3.

24 Cotton PB. Fibreoptic endoscopy and the barium meal-results and implications. Br Med J 1973; 2: 161-5.

25 Martin G. Munchausen's statistical grid, which makes all trials significant. Lancet 1984; 2: 1457.

26 Spiegelhalter DJ. Statistical methodology for evaluating gastrointestinal symptoms. Clin Gastroenterol 1985; 14: 489-515.

27 Crean GP, Spiegelhalter DJ. Symptoms of peptic ulcer. In: Brooks FP, Cohen S, Soloway RD, eds. Peptic ulcer disease. New York: Churchill Livingstone, 1985: 1-15.

28 Priebe WM, De Costa LR, Beck IT. Is epigastric tenderness a sign of peptic ulcer disease? Gastroenterology 1982; 82: 16-19.

29 Anonymous. Database on dyspepsia. [Editorial] Br Med J 1978; 1: 1163-4. 